\title{
THE FIRST WEIERSTRASS-ERDMANN CONDITION IN VARIATIONAL PROBLEMS INVOLVING DIFFERENTIAL INCLUSIONS
}

\author{
L. BAYÓN, J. M. GRAU, M. M. RUIZ, P. M. SUÁREZ
}

Abstract. In this paper, the authors continue a previous study about the broken extremals in variational problems with differential inclusions. In said paper, we presented a necessary condition for extremals with corner points that is valid for shapeable sets. This condition has been obtained by adapting a novel proof of the first Weiertrass-Erdmann condition.

In the present paper we extend the class of shapeable sets and demonstrate that the set

$$
\Omega:=\left\{z \in K C^{1}[a, b] \mid G_{1}(t, z(t)) \leqslant z^{\prime}(t) \leqslant G_{2}(t, z(t)), \forall t \in[a, b] \text { a.e. }\right\}
$$

with $G_{1}, G_{2} \in C^{1}$, is shapeable for every $t$.

Finally, we present two examples, the second being a classic engineering problem: the optimization of hydrothermal systems.

Mathematics subject classification (2000): 49K24, 49K30.

Key words and phrases: Calculus of Variations, optimization, Weierstrass-Erdmann, broken extremals, inequality constraints.

\section{REFERENCES}

[1] L. Bayón, J. M. Grau, P. M. SuÁrez, A Necessary Condition for Broken Extremals in Problems Involving Inequality Constraints, Archives of Inequalities and Applications, Vol. 1(1), (2003), 75-84.

[2] L. BAyón, J. M. Grau, P. M. SuÁreZ, A New Formulation of the Equivalent Thermal in Optimization of Hydrothermal Systems, Math. Probl. Eng., Vol. 8(3), (2002), 181-196.

[3] L. BAyón, J. M. Grau, M. M. RuIZ, P. M. SuÁreZ, A Optimization technique of Hydrothermal Systems using Calculus of Variations, Proceedings ICREPQ 2003, Spain, 2003.

[4] M. CESAR, Reformulation of the second Weierstrass-Erdmann condition, Bol. Soc. Brasil. Mat. 13(1982), no. 1, 19-23.

[5] M. CESAR, Necessary conditions and sufficient conditions of weak minimum for solutions with corner points, Bol. Soc. Brasil. Mat, 15(1984), no. 1-2, 109-135.

[6] L. Cesari, Optimization - theory and applications. Problems with ordinary differential equations, Applications of Mathematics, 17, Springer-Verlag, New York, 1983.

[7] F. H. Clarke, Inequality constraints in the calculus of variations, Canad. J. Math. 29, no. 3 (1977), 528-540.

[8] F. H. Clarke, The Erdmann condition and Hamiltonian inclusions in optimal control and the calculus of variations, Canad. J. Math. 32, no. 2 (1980), 494-509.

[9] F. H. ClaRKE AND P. D. LOEWEN, State constraints in optimal control: a case study in proximal normal analysis, SIAM J. Control Optim. 25, no. 6 (1987), 1440-1456.

[10] F. H. Clarke AND P. D. LOEWEN, An intermediate existence theory in the calculus of variations, Ann. Scuola Norm. Sup. Pisa Cl. Sci. 16, no. 4 (1990), 487-526.

[11] M. E. El-Hawary AND G. S. Christensen, Optimal economic operation of electric power systems, Academic Press, New York, 1979.

[12] G. ERDMANN, Journal für die Reine und Angewandte Mathematik, 82(1875), 21-30.

[13] B. FLODIN, Über diskontinuierliche Lösungen bei Variationsproblemen mit Gefällbeschränkung, Acta Soc. Sci. Fennicae. Nova Ser. A. 3, no. 10 (1945), 31 pp. 
[14] O. FöLLINGER, Diskontinuierliche Lösungen von Variationsproblemen mit Gefällbeschränkung, Math. Annalen, Vol. 126(1953), 466-480.

[15] I. M. Gelfand, S. V. Fomin, Calculus of Variations, Prentice-Hall, 1963.

[16] M. GiaquinTa, S. HildebrandT, Calculus of Variations, Springer-Verlag, New York, 1996.

[17] P. D. LOEWEN AND R. T. ROCKAFELLAR, New necessary conditions for the generalized problem of Bolza, SIAM J. Control Optim. 34, no. 5 (1996), 1496-1511.

[18] P. D. LOEWEN AND R. T. ROCKAFELLAR, Bolza problems with general time constraints, SIAM J. Control Optim. 35, no. 6 (1997), 2050-2069.

[19] J. NOBLE, H. SCHÄTTLER, On sufficient conditions for a strong local minimum of broken extremals in optimal control, Res. Notes Math., 396(1999), 171-179.

[20] J. Noble, H. SCHÄTtLER, Sufficient conditions for relative minima of broken extremals in optimal control theory, J. Math. Anal. Appl., 269 (2002), 98-128.

[21] N. P. OsmolovsKII, F. LeMPIO, Jacobi conditions and the Riccati equation for a broken extremal, Pontryagin Conference, 1, Optimal Control (Moscow, 1998). J. Math. Sci. (New York) 100 (2000), no. $5,2572-2592$.

[22] N. P. OsmOlovSKII, Second-order conditions for broken extremal, Calculus of variations and optimal control (Haifa, 1998), 198-216, Chapman \& Hall/CRC Res., Notes Math., 411, Chapman \& Hall/CRC, Boca Raton, FL, 2000.

[23] N. P. OsmolovskiI, F. LemPIO, Transformation of Quadratic Forms to Perfect Squares for Broken Extremals, Set-Valued Analysis 10(2) (2002), 209-232.

[24] L. A. PARS, An introduction to the calculus of variations, John Wiley \& Sons Inc., New York, 1962.

[25] M. A. SyTCHEV, Qualitative properties of solutions of the Euler equation and the solvability of one-dimensional regular variational problems in the classical sense, Siberian Math. J. 36 (1995), no. $4,753-769$.

[26] J. L. Troutman, Variational calculus with elementary convexity, Springer-Verlag, New York, 1983. 